\title{
Antimicrobial and Immune-Modulatory Effects of Vitamin D Provide Promising Antibiotics-Independent Approaches to Tackle Bacterial Infections - Lessons Learnt from a Literature Survey
}

\author{
Ainoosh Golpour, Stefan Bereswill and Markus M. Heimesaat* \\ Institute of Microbiology, Infectious Diseases and Immunology Charité - University Medicine Berlin, corporate member of Freie \\ Universität Berlin, Humboldt-Universität zu Berlin, and Berlin Institute of Health, Berlin, Germany
}

Received: 17 Jun 2019; accepted: 24 Jul 2019

\begin{abstract}
Antimicrobial multidrug-resistance (MDR) constitutes an emerging threat to global health and makes the effective prevention and treatment of many, particularly severe infections challenging, if not impossible. Many antibiotic classes have lost antimicrobial efficacy against a plethora of infectious agents including bacterial species due to microbial acquisition of distinct resistance genes. Hence, the development of novel anti-infectious intervention strategies including antibiotic-independent approaches is urgently needed. Vitamins such as vitamin D and vitamin D derivates might be such promising molecular candidates to combat infections caused by bacteria including MDR strains. Using the Pubmed database, we therefore performed an in-depth literature survey, searching for publications on the antimicrobial effect of vitamin D directed against bacteria including MDR strains. In vitro and clinical studies between 2009 and 2019 revealed that vitamin D does, in fact, possess antimicrobial properties against both Gram-positive and Gram-negative bacterial species, whereas conflicting results could be obtained from in vivo studies. Taken together, the potential anti-infectious effects for the antibiotic-independent application of vitamin D and/or an adjunct therapy in combination with antibiotic compounds directed against infectious diseases such as tuberculosis, $H$. pylori infections, or skin diseases, for instance, should be considered and further investigated in more detail.
\end{abstract}

Keywords: vitamin D, vitamin D derivates, antimicrobial effects, novel antimicrobial therapies, antimicrobial peptides, host defense peptides, multidrug-resistant bacteria

\section{Introduction}

Antimicrobial Resistance. Antimicrobial resistance (AMR) poses a serious threat to human health, limiting the effective treatment and prevention of many infections caused by bacteria, viruses, parasites, or fungi due to the emerging acquisition of resistance genes by infectious agents. Thus, AMR is a global problem that has to be addressed effectively at regional, national, and international levels [1]. Genes causing AMR can be transmitted via plasmids or acquired by chromosomal incorporation into the genome of the infectious target cell. Transfer of distinct AMR genes might result in the following events, subsequently hampering effective antimicrobial treatment: (i) mutations of the binding site, preventing the attachment of the antimicrobial compound to the infectious target cell (e.g., against beta-lactam antibiotics, streptomycin, tetracycline, and erythromycin); (ii) chemical/ conformational changes of the ribosomal molecules, subsequently blocking the binding sites of or reducing the affinity for the antimicrobial compound (e.g., the enzymatic methylation of the 23S rRNA against erythromycin); (iii) chemical/conformational changes in the antimicrobial molecule, leading to reduced or even complete loss of its efficacy (e.g., following acetylation of chloramphenicol by an acetyltransferase); (iv) expression of antimicrobial enzymes,

*Author for correspondence: Markus M. Heimesaat, Charité - University Medicine Berlin, CC5, Department of Microbiology, Infectious Diseases and Immunology, Campus Benjamin Franklin, FEM, Garystr. 5, D-14195 Berlin, Germany; Tel: +49-30-450524318; E-mail: markus.heimesaat@charite.de. inactivating the antimicrobial compound intracellularly (e.g., beta-lactamases); (v) expression of protective proteins, actively removing antimicrobials from the ribosome by energy deprivation (e.g., ribosome protecting proteins against tetracycline); and (vi) proactive expulsion of the antimicrobial out of the infectious cell (e.g., by a tetracycline efflux pump) [2].

In particular, multi-drug resistant (MDR) bacterial strains constitute major obstacles on the course of a rational, goal-directed treatment of infected and particularly severely compromised patients with immune-suppressive comorbidities, making a curative outcome for the patient utmost challenging, if not impossible. Recently, the World Health Organization (WHO) has published a list of the 12 most critical MDR bacterial groups. At the top of the list can be found Pseudomonas aeruginosa (particularly carbapenem-resistant strains), followed by Enterobacteriaceae (carbapenem-resistant or extended spectrum beta-lactamase (ESBL)-producing strains) and Acinetobacter baumannii (carbapenem-resistant). Also, a high priority of awareness require emerging Enterococcus faecium (vancomycin-resistant enterococci [VRE]), Staphylococcus aureus (methicillin-resistant [MRSA], vancomycinintermediate [VISA], and vancomycin-resistant strains), Helicobacter pylori (clarithromycin-resistant), Campylobacter including C. jejuni (fluoroquinolone-resistant and macrolideresistant), Salmonella (fluoroquinolone-resistant), and Neisseria gonorrhoeae (third-generation cephalosporin-resistant and fluoroquinolone-resistant). Resistance of the following bacterial infectious agents is considered to be of medium priority: $\quad S$. pneumoniae (penicillin-non-susceptible),

This is an open-access article distributed under the terms of the Creative Commons Attribution-NonCommercial 4.0 International License (https://creativecommons.org/licenses/by-nc/4.0/), which permits unrestricted use, distribution, and reproduction in any medium for non-commercial purposes, provided the original author and source are credited, a link to the CC License is provided, and changes - if any - are indicated. 
Haemophilus influenzae (ampicillin-resistant) and Shigella (fluoroquinolone-resistant). Hence, the emergence of MDR bacterial strains (particularly of those that have acquired plasmid encoded resistance genes) on one side and the lack of novel antimicrobial molecules in the pharmaceutical pipelines on the other contribute to this serious global threat to human health [3]. Hence, one reasonable approach to tackle this issue is to identify antibiotic-independent candidates with antimicrobial properties that might be alternative or adjunct options to combat infections by bacterial pathogens including MDR strains. Given that vitamins including vitamin $\mathrm{D}$ are well known for their health-beneficial properties $[4,5,6,7,8,9$, $10,11,12]$, a comprehensive literature survey was performed addressing the potential antimicrobial effects of vitamin D with a focus on bacterial including MDR pathogens.

Antimicrobial and Immune-Modulatory Effects of Vitamin D. Natural rich sources of vitamin D such as cod liver oil or sun exposure were used in the pre-antibiotic era for the therapy of tuberculosis or scrofula, for instance [13, 14]. After the discovery of synthetic antibiotics, the antiinfectious value of vitamin D was rather ignored for a while until the increasing cost of antibiotics and particularly the rise in antibiotic resistance led to the need to search for alternative and/or adjunct antibiotic-independent therapeutic strategies, with vitamin D supplementation as a promising option [13, $14]$.

Ultraviolet light exposure stimulates the production of vitamin D in the skin from 7-dehydrocholesterol. After catabolizing steps in defined tissues, including the liver, the biologically active form of vitamin $\mathrm{D}, 25(\mathrm{OH})$-vitamin $\mathrm{D}$, is secreted into the circulation. In the kidneys, the enzyme CYP27B1 further metabolizes 25(OH)-vitamin $\mathrm{D}$ to $1,25(\mathrm{OH})_{2}$-vitamin $\mathrm{D}$, which is the main biologically active hormonal form of vitamin D $[15,16]$. Three hormones, namely, parathormone (PTH), fibroblast growth factor 23 (FGF23), and $1,25(\mathrm{OH})_{2}$-vitamin D itself, are involved in the control of CYP27B1 activity in the renal proximal convoluted tubule, providing, to some extent, a quick response to changes in the ambient calcium and phosphate levels. Calcitonin regulates CYP27B1 activity in the proximal straight tubule. While PTH is stimulating CYP27B1 production, FGF23 is inhibiting its expression. Due to the fact that calcium and phosphate regulate the secretion of PTH and FGF23 from the parathyroid glands and bone, they also indirectly regulate CYP27B1 activity in the kidneys [17].

Previous reports documented health-beneficial effects of vitamins in general $[4,5,6,7,8,9,10,11,12]$. Among these, vitamin D has been shown to alleviate several morbidities, including bacterial infections caused by Mycobacterium tuberculosis and $S$. aureus $[8,18,19,20,21,22]$. In addition, vitamin $\mathrm{D}$ has been shown to support clearance of $P$. aeruginosa by macrophages $[8,23]$ and to exert direct bactericidal activity against Helicobacter pylori [6, 7, 24], as well as against Streptococcus mutans [4]. Notably, in vitro studies revealed that the expression of distinct virulence factors in Porphyromonas gingivalis, as well as bacterial growth, could be inhibited by vitamin D application [25].

The immune-modulatory properties of vitamin $\mathrm{D}$ are exerted following binding to the vitamin D receptor (VDR) that is expressed by numerous innate and adaptive immune cell subsets, including monocytes, macrophages, dendritic cells, naïve CD4+ T cells, T helper (Th) 1 cells and Th2 cells [26]. The VDR constitutes a nuclear hormone receptor, and its activation leads to the induction of chromatin remodeling, resulting in either activated or suppressed expression of distinct genes [26]. After binding on VDR, vitamin D causes hetero-dimerization with the retinoic acid receptor (RXR), affecting gene expression either through binding of the VDR/ RXR complex to vitamin D response elements (VDREs) of the target genes or association with other transcription factors, preventing binding and activation of target genes [26, 27]. Immune-related genes, such as CD14 [28], $\beta$-defensin (DEFB4) [29], TNF- $\alpha$ [30], Toll-like receptor (TLR)-4 [28], hepcidin (HAMP) [31], co-stimulatory molecules involved in antigen presentation such as CD86, CD80, and CD40 [32], Th1 cytokines (IL-2, IL-12, and IFN- $\gamma$ ), and Th2 cytokines (IL-4, IL-5 and IL-10) [33, 34, 35], represent all vitamin D target genes. The action of vitamin $\mathrm{D}$ is not restricted to the modulation of respective gene expression. The VDR activation further stimulates the differentiation of monocytes into mature macrophages and induces macrophage chemotactic ability and phagocytosis of $M$. tuberculosis [36, 37, 38, 39]. Furthermore, $1,25(\mathrm{OH})_{2}$-vitamin D has been shown to modulate cathelicidin antimicrobial peptide (CAMP) gene expression in innate immune cells such as monocytes and macrophages. CAMP can be found in the lysosomes of macrophages, as well as neutrophils. Hence, in addition to acting as chemo-attractants of other immune cells, $1,25(\mathrm{OH})_{2}$-vita$\min \mathrm{D}$ as the main active hormonal form of vitamin $\mathrm{D}[15$, 40] exerts pivotal roles in innate immunity with broad antimicrobial effects [31, 41].

The molecular mechanisms underlying the antimicrobial effects of vitamin D involve distinct antimicrobial peptides (AMPs) [42], also known as host defense peptides (HDPs), and will be more comprehensively addressed later on. In brief, these relatively small $(<10 \mathrm{kDa})$ AMPs are known for their net positive charge and amphipathicity of the cell $[43,44]$ and can be divided into two groups, namely, cathelicidins and defensins [45, 46, 47]. Many pathogenic bacteria, such as, $N$. gonorrhoeae, Vibrio cholerae, enterotoxigenic Escherichia coli and Shigella flexneri have been shown to be tackled by HDPs [48, 49, 50, 51]. Previous studies further revealed that induction of endogenous HDP production exerted enhanced antimicrobial capacities in rabbits and chicken [52, 53, 54, 55, 56]. On the other hand, infections and injuries lead to an increased expression of HDPs with an unwanted exaggerated immune response harming the vertebrate host. Vitamin D3 and the short chain fatty acid butyrate, however, are capable of inducing HDPs without provoking inflammatory responses due to an orchestrated and well-balanced interaction with commensal microbes $[55,57]$.

\section{Methods}

Inclusion and Exclusion Criteria. The main inclusion criteria for the literature survey were in vitro and in vivo, such as clinical infection studies with bacterial strains and antimicrobial effects of vitamin D (active form) and its derivates. In vitro and in vivo studies addressing anti-viruses and anti-fungi properties of vitamin D were excluded.

Searching Strategy. Using the MEDLINE database PubMed, we performed an online literature survey of publications investigating the antibacterial effect of vitamin D directed against bacteria including MDR strains. Publications of the past 10 years (i.e., between 2009 and 2019) were considered, and the following steps (as summarized in Table 1) were carried out using Boolean logic through the advance search history option on the PubMed database.

Firstly, using the Boolean operator OR, which ensured that synonyms were included, the literature was searched for publications with the key words "Vitamin D OR vitamin D3 OR Cholecalciferol OR Calciol". By using the MeSH term, this method was further enhanced in order to find publications with any possible variations of the name of vitamin D. 
Table 1. Boolean logic search results on PubMed

\begin{tabular}{|c|c|c|c|c|}
\hline Search & Add to builder & Query & Items found & Time \\
\hline$\# 7$ & Add & $\begin{array}{l}\text { Search ((vitamin } \mathrm{d} \text { or vitamin } \mathrm{d} 3 \text { or cholecalciferol or calciol })) \text { AND ((antimicrobial or antibiotic)) AND } \\
\text { ((antibiotic resistance)) Filters: published in the last } 10 \text { years }\end{array}$ & 29 & $08: 42: 35$ \\
\hline \#6 & Add & $\begin{array}{l}\text { Search ((vitamin d or vitamin d3 or cholecalciferol or calciol)) AND ((antimicrobial or antibiotic)) AND } \\
((\text { antibiotic resistance)) }\end{array}$ & 46 & 08:42:09 \\
\hline$\# 5$ & Add & Search antibiotic resistance & 192750 & $08: 41: 25$ \\
\hline \#4 & Add & Search ((vitamin $\mathrm{d}$ or vitamin $\mathrm{d} 3$ or cholecalciferol or calciol) $)$ AND ((antimicrobial or antibiotic)) & 3337 & 08:39:31 \\
\hline \#3 & Add & Search antimicrobial or antibiotic & 1751536 & $08: 37: 43$ \\
\hline \#2 & Add & Search vitamin $d$ OR vitamin $d 3$ OR cholecalciferol OR calciol & 82904 & 08:36:59 \\
\hline$\# 1$ & Add & Search vitamin $\mathrm{d}$ & 80994 & 08:35:17 \\
\hline
\end{tabular}

Secondly, the search term "antimicrobial or antibiotic" was employed to identify studies that centered and focused on antibiotic properties. Thirdly, the term "antibiotic resistance" was included to assure that investigations on resistant bacteria were also contained. Finally, in order to limit the results, all three search terms were combined through the Boolean operator "AND".

Thereby, 46 items could be found. Studies published within the previous 10 years were searched for yielding 29 articles, all of which were carefully evaluated, considering the abovementioned inclusion and exclusion criteria. Some of the articles were withdrawn because they were relating to viruses or fungi; others did not focus on the antimicrobial effect of vitamin D. Finally, 6 articles remained. Nevertheless, withdrawn articles provided helpful information for the understanding of the immune-modulatory functions of vitamin $\mathrm{D}$, in particular, and were included in the discussion.

Data Extraction. In order to provide a systematic literature search, all the information gained from the studies was carefully evaluated and selected, considering the defined inclusion and exclusion criteria in the first line. The type of the study, the characteristics of the populations participating in the study, the main findings of each publication, how relevant the findings were related to the addressed topic, and how the different parameters were measured, as well as possible study errors or derived inconsistencies, were additionally taken into consideration.

Ethics Statement. Not applicable (literature survey).

\section{Results}

Searching Results. An E. coli strain with a K1 capsule was isolated from a neonate suffering from meningitis and further used in an in vitro study. Microglia were prepared from vitamin D-deficient mice and from wild-type counterparts, incubated with the E.coli isolate, and stimulated with synthetic TLR-1/-2, TLR-3, TLR-4, or TLR-9 agonists. In both vitamin D-deficient and wild-type mice, the $E$. coli eradication rates increased upon stimulation with different TLR agonists in a dose-dependent manner. The study further revealed that high dose stimulations of incubated microglia with TLR-3, TLR-4, and TLR-9 ligands, but not with TLR-1/-2 agonists, cause significant increases in the E. coli phagocytosis rates in the microglia derived from wild-type but not from vitamin Ddeficient mice, supporting the anti-microbial effects of vitamin $\mathrm{D}[5]$.

Another study addressed the antibacterial effect of exogenous vitamin D against Helicobacter pylori Sydney strain 1 both in vitro and in vivo. Firstly, the pathogen was used to induce chronic gastritis in the stomach of mice that were either subjected to vitamin D or placebo treatment. Furthermore, in order to investigate the antimicrobial action of vitamin $\mathrm{D}$ on intracellular $H$. pylori replication, healthy human gastric epithelial cells (HFE145) were infected with H. pylori for $72 \mathrm{~h}$. Two months post-infection, gastric $H$. pylori burdens were lower in vitamin D mice, as compared to placebo-treated mice. In support, the intracellular H. pylori replication could be dampened upon $1,25(\mathrm{OH})_{2}$-vitamin D application, as compared to placebo stimulation in vitro [6].

In a clinical study including $150 \mathrm{H}$. pylori-infected patients from Egypt, the pathogen-eradicating effects of vitamin D were assessed. Before the start of a 14-day triple therapy (with clarithromycin, amoxicillin, and omeperazole) and 4 weeks thereafter, the $25(\mathrm{OH})$-vitamin D serum concentrations were measured in each patient. Of note, vitamin D levels were significantly higher in the successfully $H$. pylori eradicated cohort as compared to the triple therapy non-responders. Whereas two thirds of patients from the failed treatment group suffered from overt vitamin D deficiency, this held true for only $9.5 \%$ of the $H$. pylori-negative patients. Remarkably, a 25(OH)-vitamin D serum deficiency could be found in more than $25 \%$ of all patients included in the survey [7].

In an observational study from Japan, however, the antimicrobial effects of vitamin D could not be confirmed, given that even a negative correlation between vitamin D-rich diet/ serum-vitamin D levels and anti-H. pylori effects could be assessed. Three-hundred-eighty-nine $H$. pylori infected patients with diagnosed gastritis received a triple $H$. pylori eradication therapy, consisting of two antibiotics, namely, amoxicillin with clarithromycin or metronidazole, and a proton pump inhibitor (PPI). The daily vitamin D intake of the participants was determined applying a food-frequency questionnaire. The results revealed that the estimated daily intake of vitamin D was significantly lower in the successfully treated group than in the triple therapy non- responding cohort [58].

A screening series of 853 drugs approved by the Food and Drug Administration (FDA) revealed that 126 compounds, which turned out to be vitamin D analogues, displayed antimicrobial activities directed against $S$. mutans due to planktonic cell lysis. In a further in-depth evaluation of the structure of the respective compounds, the 3 compounds with the most potent antibacterial activities were the vitamin D analogues, namely, alpha-calcidol and doxercalciferol, and vitamin D. Antimicrobial susceptibility assays with $S$. mutans cultures revealed minimal inhibitory concentrations (MICs) of $16 \mu \mathrm{g} / \mathrm{mL}$ of the vitamin D derivates under investigation [4].

Lipid-soluble compounds including vitamin $\mathrm{D}$ have been found to cause changes in the fluidity of the bacterial membrane, facilitating the penetration of synthetic substances, including antibiotics $[59,60]$. Therefore, a recent in vitro study addressed the antibacterial activity and antibiotic-modifying effects of vitamin D directed against clinical MDR P. aeruginosa, E. coli, and S. aureus strains. Measurement of the MICs of the aminoglycosides amikacin, neomycin, and gentamicin applying the broth microdilution assay revealed that vitamin $\mathrm{D}$ alone did not exhibit antimicrobial effects against the 3 MDR bacterial isolates. Addition of vitamin D to amikacin or 
gentamicin, however, could lower the MIC of the respective aminoglycosides against the clinical MDR $P$. aeruginosa strain by a factor $<0.25$ and hence improve the antimicrobial susceptibility more than four times. Notably, the combination of vitamin D and neomycin even had an antagonistic effect, thus, reducing the effectiveness of the antibiotics. The synergistic antimicrobial effects of vitamin D with the aminoglycosides against the $E$. coli strain were less pronounced as compared to those against $P$. aeruginosa and virtually missing in case of $S$. aureus [8].

Further Findings from Studies Providing Useful Knowledge Regarding the Multifaceted Properties of Vitamin D in Health and Disease. As aforementioned, the antibacterial effects of vitamin $\mathrm{D}$ are also due to the induced expression of antimicrobial peptides such as cathelicidin and $\beta$-defensin, further providing synergistic antimicrobial properties [61]. A recent study revealed positive associations between synthetic calcium channel blockers, expression of cathelicidin and $\beta$ defensin, and intracellular $1,25(\mathrm{OH})_{2}$-vitamin D concentrations in immune-compromised patients during sepsis [62]. The authors hypothesized that septic patients suffering from infections by antibiotic-resistant pathogens making the channels sensitive might benefit from calcium channelblocking medications [62]. However, the specific relationship between intracellular calcium concentrations, vitamin $\mathrm{D}$, and calcium channel blockers still needs to be investigated in more detail.

Further studies addressed potential associations between sepsis, vitamin D concentrations, kidney function, and mortality. In a study published in 2009, 24 septic patients admitted to the intensive care unit (ICU), 5 non-septic ICU control patients, and 11 healthy subjects were included and subjected to comparative analyses of vitamin D serum concentrations, kidney function, and mortality. Results revealed a positive correlation between $25(\mathrm{OH})$-vitamin D serum concentrations and of the antimicrobial peptide cathelicidin (LL-37) [63]. Other reports hypothesized that kidney failure might be considered a risk factor for infection and that the retention of phosphorus with lowering calcium levels were associated with higher mortality $[64,65]$. A potential mechanistic explanation for this association might be the following:

$25(\mathrm{OH})$-vitamin D is filtered in complex with the vitamin D binding protein and can be reabsorbed from the glomerular filtrate [66]. After filtration, in which the megalin protein plays a major role, the binding protein is degraded, the $25(\mathrm{OH})$-vitamin $\mathrm{D}$ is converted into $1,25(\mathrm{OH})_{2}$-vitamin $\mathrm{D}$, and both $25(\mathrm{OH})$-vitamin $\mathrm{D}$ and $1,25(\mathrm{OH})_{2}$-vitamin $\mathrm{D}$ are reabsorbed into the circulation $[65,66]$. Some knowledge of renal failure as a risk factor for infection could be obtained by studying the response to phosphorus retention in the combined effects of PTH, FGF23, and Klotho [67]. Kidney failure with vitamin D deficiency stimulates the release of FGF23, which cooperates with the anti-aging protein Klotho for elimination of retained phosphorus if vitamin D is replaced [64, 67, 68]. PTH and FGF 23 are in the position to increase, at the proximal tubular site, the phosphate transport to decrease phosphorus reabsorption. However, while PTH contributes to activation of 1-alpha-hydroxylase, FGF23 (in competition) inhibits activation of this enzyme hampering, at the same time, the formation of the active form of vitamin D. This leads to adverse, if not even fatal, consequences, pointing towards the pivotal role of active vitamin D within this pathophysiological scenario [64, 67]. Considering the link between phosphorus and calcium $[64,65]$, as well as the relationship between vitamin $\mathrm{D}$ and phosphorus [64, 67, 68], this could further support the orchestrated interaction between vitamin $\mathrm{D}$, calcium, and host defense peptides to protect from human infections.
A previous publication addressed the correlation between shigellosis and antimicrobial peptides [69]. Shigella infections usually cause fever together with mucoid and hemorrhagic stool. In response to Shigella infection, gut epithelial cells induce mucosal secretion of AMPs, which exert antibacterial lytic effects and recruit immune cells to the site of the infection [50]. AMPs further share important roles in chemotaxis, angiogenesis, and immune cell activation [70]. It is hypothesized that deficiencies in Th17 cells, which are important for epithelial immunity against pathogens, lead to deficiency in AMPs resulting in reduced pathogenic antigen presentation at epithelial surfaces [69, 71, 72, 73, 74]. If this hypothesis is correct, compounds with the ability to induce epithelial AMP expression (such as butyrate, phenyl-butyrate and vitamin D, for instance) could "by-pass" a deficient Th17-cell compartment and be used as a novel adjunct and antibiotic-independent strategy to combat infections [69].

To date, a potential link between vitamin D deficiency and susceptibility towards tuberculosis could be found in several studies. An epidemiological study revealed that the incidence of tuberculosis was two times lower in white populations with increased levels of vitamin D than in black populations [75]. Higher incidences of tuberculosis during spring and early summer also support an inverse correlation between vitamin D levels and tuberculosis [76, 77]. Other studies, however, showed that both lower and higher circulating levels of vitamin D might impact the progression of active tuberculosis $[78,79]$. Furthermore, an in vitro study revealed that vitamin D stops the entry of M. tuberculosis into and the bacterial survival within the cell [80] by promoting the fusion of phagosomes and lysosomes in macrophages and subsequently reducing the viability of $M$. tuberculosis [81]. In addition, vitamin D induces the transcription of AMPs, further restricting the intracellular growth of M. tuberculosis [61, 82, 83]. Moreover, high intracellular concentrations of iron have been reported to enhance the mycobacterial growth and survival $[31,84]$, given that vitamin D down-regulates the HAMP expression, leading to decreased intracellular iron concentrations resulting in suppressed survival of intracellular bacteria including M. tuberculosis [85]. Furthermore, vitamin D modulates both innate and adaptive immune responses resulting in dampened inflammatory sequelae of infection [86, 87, 88, 89, 90]. Several clinical trials have used vitamin D supplements as an adjuvant supplementation for the therapy of tuberculosis. Whereas some studies revealed better treatment responses [91, 92, 93, 94], others did not [79, 95]. Therefore, well-designed studies should further unravel potential antibiotic-independent approaches including vitamin D supplementation as an adjunct treatment option to combat tuberculosis particularly caused by MDR strains.

\section{Discussion}

Main Findings of the Literature Survey. The performed literature survey revealed potent antibacterial effects of vitamin D directed against a multitude of both Gram-positive and Gram-negative bacterial strains including S. mutans, $P$. aeruginosa, E. coli, M. tuberculosis, H. pylori, and Shigella as shown in vitro and in vivo. Of note, potent synergistic antibacterial effects of vitamin $\mathrm{D}$ in combination with aminoglycosides against clinical MDR P. aeruginosa and E. coli strains could also be found.

One in vivo study, however, revealed rather contrasting results given an even negative relationship between high dietary vitamin $\mathrm{D}$ intake and successful eradication of $H$. pylori in Japanese patients. There are several limitations that need to be taken into consideration and that might explain discrepant 
results. For instance, in this study, antibiotic resistance of $H$. pylori was not assessed in the Japanese study cohort [58]. Furthermore, besides study design many dependent and independent variables might be responsible for inconsistencies in the assessed parameters, defined outcome, ethnicity, and genetic, as well as the epigenetic factors within the respective study populations among many others. Nevertheless, overall, there is a strong body of evidence supporting the health-beneficial roles of exogenous vitamin $\mathrm{D}$ opening novel avenues for the treatment and even prevention of many human morbidities including infections with (resistant) bacterial strains.

Open Questions and Areas for Future Research. In the present literature survey, the antimicrobial effects of vitamin D were demonstrated in very heterogeneous in vitro and in vivo studies of limited numbers. Due to this heterogeneity a definitive conclusion about the antimicrobial effects of vitamin $\mathrm{D}$ cannot be drawn. The molecular mechanisms underlying the effects of vitamin $\mathrm{D}$ in patients with distinct morbidities caused by bacteria including MDR strains needs to be further unraveled. Moreover, in the past 10 years, only one single in vitro study addressing synergistic antibacterial properties of vitamin $\mathrm{D}$ in combination with synthetic antibiotic compounds against MDR bacterial strains exists to date [8]. Hence, more well-designed studies should be conducted to explore the interaction between vitamin $\mathrm{D}$, antibiotics, and eradication therapies of MDR pathogens in more detail. Considering the dynamics in the emergence and spread of MDR bacterial strains, the lack of novel antimicrobial molecules in the pharmaceutical pipelines and, hence, the progressive global threat due to more and more limited options to combat potentially life-threatening infectious diseases in the near future should further emphasize that this innovative step of research and clinical application is urgently needed.

Limitations of the Literature Survey. Due to different factors during the research or due to mistakes in the studies that were carried out and published, wrong conclusions may arise. Therefore, it is important to carefully consider and review the information taken from the studies. The fact that some clinical trials have been carried out in a very distinct population (e.g., Japanese population) or in a limited cohort (low numbers of samples or patients) constitutes a profound limitation. It should be also mentioned that the present work has methodological limitations. Although the effort to reach a search strategy has been made, which would be as sensitive as possible, there might be relevant studies that have not been included. Of note, the quality assessment of the included studies was performed by a single investigator.

Antimicrobial Peptides and Vitamin D - Future Perspectives as Treatment Options. HDPs including AMPs are molecules with immune-modulatory properties, competent to regulate innate and adaptive immune responses, and lyse a broad range of microorganisms such as bacteria, fungi, parasites, and viruses [44, 45, 96, 97]. Interestingly, AMPs exert potent antagonistic effects directed against lipopolysaccharide (LPS), the main important cell wall constituent and pathogenicity factor of Gram-negative bacteria [98]. In addition, it has been shown that AMPs act as potent inhibitors of microbial biofilms with antibiotic tolerance [99, 100]. Furthermore, AMPs stimulate cell proliferation, promote wound healing, and kill cancer cells [44, 45, 96]. Thus, AMPs play primary roles in host protection against microbial infections. In support, the beneficial anti-inflammatory effects of AMPs in skin infections diseases such as psoriasis [101], atopic dermatitis [102], rosacea [103], Kostmann's syndrome [104], severe congenital neutropenia [105], lupus erythematodes [106], acne vulgaris [107], folliculitis [108], scleroderma [109], cutaneous T-cell lymphoma [110], or basal cell carcinoma [111], in autoimmune disorders [112, 113], respiratory infectious diseases [114], and cancer [115, 116, $117,118]$ have been shown in several studies. The underlying antimicrobial mechanism might be explained by the fact that the AMPs are cationic and have an affinity to the negatively charged bacterial membrane resulting in its disruption and bacterial cell lysis [69]. Thus, stimulation of endogenous AMP production represents a promising approach for treating human morbidities including infections. The link between AMPs and vitamin D might be due to the following mechanisms: vitamin D is known to synergize with 4phenylbuturate (PBA), a substance competent to induce expression of AMPs [119]. In addition, vitamin D itself can also up-regulate the expression of the AMP cathelicidin LL-37 [120]. An adjuvant therapy of PBA and $1,25(\mathrm{OH})_{2}$-vitamin with first line anti-mycobacterial compounds, such as rifampicin, isoniazid, ethambutol, and pyrazinamide, revealed positive effects in tuberculosis treatment [121]. This further provides strong evidence that AMP induction or modulation in combination with conventional antibiotics might be reasonable options to combat many infections. Therefore, the dietary modulation of HDP synthesis through increasing daily vitamin D intake, for instance, might be a novel promising, antibiotics-independent approach for antimicrobial therapy $[122,123]$. Although this scientific research field has yet to be elucidated in more detail, the studies that have been already done set the bases for novel developments and open the door for the use of AMP inducers as dietary supplements to treat infections and other human diseases including skin diseases, autoimmune disorders, and cancer $[111,112,113,114,115$, $122]$.

\section{List of Abbreviations}

AMP: antimicrobial peptide

AMR: antimicrobial resistance

CAMP: Cathelicidin antimicrobial peptide

DEFB4: beta-defensin

ESBL: extended spectrum beta-lactamase

FGF23: fibroblast growth factor 23

FDA: Food and Drug Administration

HAMP: hepcidin

HDP: host defense peptides

ICU: intensive care unit

LPS: lipopolysaccharide

MRSA: methicillin-resistant Staphylococcus aureus.

MIC: minimal inhibitory concentration

MDR: multi-drug resistant

PTH: parathormone

PBA: 4-phenylbuturate

PPI: proton pump inhibitor

RXR: retinoic acid receptor

Th: T helper

TLR: Toll-like receptor

VISA: vancomycin-intermediate Staphylococcus aureus

VRE: vancomycin-resistant enterococci

VDR: vitamin D receptor

VDRE: vitamin D response element

WHO: World Health Organization

\section{Funding Sources}

This work was supported by grants from the German Federal Ministries of Education and Research (BMBF) in the frame of the zoonoses research consortium PAC-Campylobacter (IP7/ 01KI1725D) and from the Federal Ministry for 
Economic Affairs and Energy following a resolution of the German National Parliament, Deutscher Bundestag (ZIM, ZF4117908 AJ8) to SB and MMH.

The funders had no role in study design, data collection and analysis, decision to publish, or preparation of the manuscript.

\section{Authors' Contributions}

AG conceived and designed the survey, wrote the paper. $\mathrm{SB}$ provided critical advise in design of the survey, edited paper. MMH supervised the survey, co-wrote the paper.

\section{Conflict of Interests}

\section{$\mathrm{SB}$ and $\mathrm{MMH}$ are Editorial Board members.}

\section{References}

1. Prestinaci F, Pezzotti P, Pantosti A. Antimicrobial resistance: a global multifaceted phenomenon. Pathog Glob Health. 2015;109:309-18.

2. Fritsche O. Springer-Verlag GmbH. Mikrobiologie. Genetik. Berlin; Heidelberg: Springer Spektrum; 2016. p. 139-98

3. Tacconelli E, Magrini N. Global priority list of antibiotic-resistan bacteria to guide research, discovery, and development of new antibiotics. WHO. [2017]. Available from: http://www.who.int/medicines/publications/ WHO-PPL-Short Summary 25Feb-ET NM WHO.pdf?ua=1.

4. Saputo S, Faustoferri RC, Quivey RJu. Vitamin D Compounds Are Bactericidal against Streptococcus mutans and Target the Bacitracin-Associated Efflux System. Antimicrob Agents Chemotherapy. 2017;62:e01675-17.

5. Djukic M, Onken ML, Schütze S, Redlich S, Götz A, Hanisch UK, et al. Vitamin D Deficiency Reduces the Immune Response, Phagocytosis Rate, and Intracellular Killing Rate of Microglial Cells. Infect Immun. 2014;82:2585-94.

6. Hu W, Zhang L, Li MX, Shen J, Liu XD, Xiao ZG, et al. Vitamin D3 activates the autolysosomal degradation function against Helicobacter pylori through the PDIA3 receptor in gastric epithelial cells. Autophagy. 2019; $15: 707-25$

7. El Shahawy MS, Hemida MH, El Metwaly I, Shady ZM. The effect of vitamin D deficiency on eradication rates of Helicobacter pylori infection. JGH Open. 2018:2:270-75.

8. Andrade JC, Morais Braga MFB, Guedes GMM, Tintino SR, Freitas MA, Quintans LJJr, et al. Cholecalciferol, Ergosterol, and Cholesterol Enhance the Antibiotic Activity of Drugs. Int J Vitam Nutr Res. 2019; 24:1-7.

9. Ambrożewicz E, Muszyńska M, Tokajuk G, Grynkiewicz G, Žarković N, Skrzydlewska E. Beneficial Effects of Vitamins K and D3 on Redox Balance of Human Osteoblasts Cultured with Hydroxyapatite-Based Biomaterials. Cells. 2019;8:E325.

10. Wimalawansa SJ.Vitamin D Deficiency: Effects on Oxidative Stress, Epigenetics, Gene Regulation, and Aging. Biology (Basel). 2019;8(2):E30.

11. Buesing S, Costa M, Schilling JM, Moeller-Bertram T. Vitamin B12 as a Treatment for Pain. Pain Physician. 2019;22:E45-52.

12. Blaszczak W, Barczak W, Masternak J, Kopczyński P, Zhitkovich A, Rubiś B. Vitamin C as a Modulator of the Response to Cancer Therapy. Molecules. 2019;24:E453.

13. Rook GA, Steele J, Fraher L, Barker S, Karmali R., O'Riordan J, et al. Vitamin D3, gamma interferon, and control of proliferation of Mycobacterium tuberculosis by human monocytes. Immunology. 1986;57:159-63.

14. Guy RA. The history of cod liver oil as a remedy. Am. J Dis Child. 1923;26:112-6.

15. DeLuca HF. Vitamin D: the vitamin and the hormone. Fed Proc. 1974;33:2211-9.

16. Zehnder D, Bland R, Walker EA, Bradwell AR, Howie AJ, Hewison $\mathrm{M}$, et al. Expression of 25-hydroxyvitamin D3-1alpha-hydroxylase in the human kidney. J Am Soc Nephrol. 1999;10:2465-73.

17. Bikle DD, Patzek S, Wang Y. Physiologic and pathophysiologic roles of extra renal CYP27b1: Case report and review. Bone Rep. 2018;8:255-67.

18. Selvaraj P, Harishankar M, Afsal K. Vitamin D: Immuno-modulation and tuberculosis treatment. Can J Physiol Pharmacol. 2015;93:377-84.

19. Zeng J, Wu G, Yang W, Gu X, Liang W, Yao Y, et al. A serum vitamin D level $<25 \mathrm{nmol} / 1$ pose high tuberculosis risk: a meta-analysis. PLoS One. 2015; $10: \mathrm{e} 0126014$

20. Tukvadze N, Sanikidze E, Kipiani M, Hebbar G, Easley KA, Shenvi N, et al. High-dose vitamin D3 in adults with pulmonary tuberculosis: a doubleblind randomized controlled trial. Am J Clin Nutr. 2015;102:1059-69.

21. Wang JW, Hogan PG, Hunstad DA, Fritz SA. Vitamin D sufficiency and Staphylococcus aureus infection in children. Pediatr Infect Dis J. 2015;34:544-5.

22. Thomason J, Rentsch C, Stenehjem EA, Hidron AI, Rimland D. Association between vitamin D deficiency and methicillin-resistant Staphylococcus aureus infection. Infection. 2015;43:715-22.

23. Nouari W, Ysmail-Dahlouk L, Aribi M. Vitamin D3 enhances bactericidal activity of macrophage against Pseudomonas aeruginosa. In Immunopharmacol. 2016;30:94-101.

24. Hosoda K, Shimomura H, Wanibuchi K, Masui H, Amgalanbaatar A, Hayashi S, et al. Identification and characterization of a vitamin D decomposition product bactericidal against Helicobacter pylori. Sci Rep. 2015;5:8860.
25. Grenier D, Morin MP, Fournier-Larente J, Chen H. Vitamin D inhibits the growth of and virulence factor gene expression by Porphyromonas gingivalis and blocks activation of the nuclear factor kappa B transcription factor in monocytes. J Periodontal Res. 2016;51:359-65.

26. Karlic H, Varga F. Impact of vitamin D metabolism on clinical epigenetics. Clin Epigenetics. 2011;2:55-61.

27. Takeuchi A, Reddy GS, Kobayashi T, Okano T, Park J, Sharma S. Nuclear factor of activated T cells (NFAT) as a molecular target for 1alpha,25dihydroxyvitamin D3-mediated effects. J Immunol. 1998;160:209-18.

28. Oberg F, Botling J, Nilsson K. Functional antagonism between vitamin D3 and retinoic acid in the regulation of CD14 and CD23 expression during monocytic differentiation of U-937 cells. J Immunol. 1993;150:3487-95.

29. Wang TT, Tavera-Mendoza LE, Laperriere D, Libby E, MacLeod NB, Nagai Y, et al. Large-scale in silico and microarray-based identification of direct 1,25-dihydroxyvitamin D3 target genes. Mol Endocrinol. 2005;19:268595

30. Cohen-Lahav M, Shany S, Tobvin D, Chaimovitz C, Douvdevani A Vitamin D decreases NFkappaB activity by increasing IkappaBalpha levels. Nephrol Dial Transplant. 2006;21:889-97.

31. Sow FB, Florence WC, Satoskar AR, Schlesinger LS, Zwilling BS, Lafuse WP. Expression and localization of hepcidin in macrophages: a role in host defense against tuberculosis. J Leukoc Biol. 2007;82:934-45.

32. Adorini L, Penna G. Dendritic cell tolerogenicity: a key mechanism in immunomodulation by vitamin $\mathrm{D}$ receptor agonists. Hum Immunol. 2009;70:345-52.

33. Cippitelli M, Santoni A. Vitamin D3: a transcriptional modulator of the interferon-gamma gene. Eur J Immunol. 1998;28:3017-30.

34. Boonstra A, Barrat AF, Crain C, Heath VL, Savelkoul HF, O'Garra A. 1alpha,25-Dihydroxyvitamin d3 has a direct effect on naive CD4 (+) T cells to enhance the development of Th2 cells. J Immunol. 2001;167:4974-80.

35. D’Ambrosio D, Cippitelli M, Cocciolo MG, Mazzeo D, Di Lucia P, Lang R, et al. Inhibition of IL-12 production by 1,25-dihydroxyvitamin D3. Involvement of NF-kB downregulation in transcriptional repression of the p40 gene. J Clin Investig. 1998;101:252-62.

36. Bar-Shavit Z, Teitelbaum SL, Reitsma P, Hall A, Pegg LE, Trial J, et al. Induction of monocytic differentiation and bone resorption by 1,25 dihydroxyvitamin D3. Proc Natl Acad Sci U S A. 1983;80:5907-11.

37. Rigby WF, Shen L, Ball ED, Guyre PM, Fanger MW. Differentiation of a human monocytic cell line by 1,25-dihydroxyvitamin D3 (calcitriol): a morphologic, phenotypic, and functional analysis. Blood. 1984;64;1110-5.

38. Xu H, Soruri A, Gieseler RK, Peters JH. 1,25-Dihydroxyvitamin D3 exerts opposing effects to IL-4 on MHC class-II antigen expression, accessory activity, and phagocytosis of human monocytes. Scand J Immunol. 1993;38:535-40

39. Kassebaum NJ, Bertozzi-Villa A, Coggeshall MS, Shackelford KA, Steiner C, Heuton KR, et al. Global, regional, and national levels and causes of maternal mortality during 1990-2013: a systematic analysis for the Global Burden of Disease Study 2013. Lancet. 2014;384:980-1004.

40. Bah SY, Dickinson P, Forster T, Kampmann B, Ghazal P. Immune oxysterols: Role in mycobacterial infection and inflammation. J Steroid Biochem Mol Biol. 2017;169:152-63.

41. Lowry MB, Guo C, Borregaard N, Gombart AF. Regulation of the human cathelicidin antimicrobial peptide gene by $1 \alpha, 25$-dihydroxyvitamin D3 in primary immune cells. J. Steroid Biochem Mol Biol. 2014;143:183-91.

42. Gombart AF, Borregaard N, Koeffler HP. Cathelicidin antimicrobial peptide (CAMP) gene is a direct target of the vitamin D receptor and is strongly up-regulated in myeloid cells by 1,25-dihydroxyvitamin D3. FASEB J. 2005; 19:1067-77.

43. Fjell CD, Hiss JA, Hancock RE, Schneider G. Designing antimicrobial peptides: form follows function. Nat Rev Drug Discov. 2011;11:37-51.

44. Steinstraesser L, Kraneburg U, Jacobsen F, Al-Benna S. Host defense peptides and their antimicrobial-immunomodulatory duality. Immunobiology. 2011;216:322-33

45. Lai Y, Gallo RL. AMPed up immunity: how antimicrobial peptides have multiple roles in immune defense. Trends Immunol. 2009;30:131-41.

46. Selsted ME, Ouellette AJ. Mammalian defensins in the antimicrobial immune response. Nat Immunol. 2005; 6:551-7.

47. Zanetti M. Cathelicidins, multifunctional peptides of the innate immunity. J Leukoc Biol. 2004;75:39-48.

48. Bergman P, Johansson L, Asp V, Plant L, Gudmundsson GH, Jonsson $\mathrm{AB}$, et al. Neisseria gonorrhoeae downregulates expression of the human antimicrobial peptide LL-37. Cell Microbiol. 2005;7:1009-17.

49. Chakraborty K, Ghosh S, Koley H, Mukhopadhyay AK, Ramamurthy T, Saha DR, et al. Bacterial exotoxins downregulate cathelicidin (hCAP-18/ LL-37) and human beta-defensin 1 (HBD-1) expression in the intestinal epithelial cells. Cell Microbiol. 2008;10:2520-37.

50. Islam D, Bandholtz L, Nilsson J, Wigzell H, Christensson B, Agerberth $B$, et al. Downregulation of bactericidal peptides in enteric infections: a nove immune escape mechanism with bacterial DNA as a potential regulator. Nat Med. 2001;7:180-5.

51. Sperandio B, Regnault B, Guo J, Zhang Z, Stanley SLJr, Sansonetti PJ, et al. Virulent Shigella flexneri subverts the host innate immune response through manipulation of antimicrobial peptide gene expression. J Exp Med. 2008;205:1121-32.

52. Raqib R, Sarker P, Bergman P, Ara G, Lindh M, Sack DA, et al. Improved outcome in shigellosis associated with butyrate induction of an endogenous peptide antibiotic. Proc Natl Acad Sci U S A. 2006;103:9178-83.

53. Sadeyen JR, Trotereau J, Protais J, Beaumont C, Sellier N, Salvat G, et al. Salmonella carrier-state in hens: study of host resistance by a gene expression approach. Microbes Infect. 2006;8:1308-14.

54. Sarker P, Ahmed S, Tiash S, Rekha RS, Stromberg R, Andersson J, et al. Phenylbutyrate counteracts Shigella mediated downregulation of 
cathelicidin in rabbit lung and intestinal epithelia: a potential therapeutic strategy. PLoS One. 2011;6:e20637.

55. Sunkara LT, Achanta M, Schreiber NB, Bommineni YR, Dai G, Jiang $\mathrm{W}$, et al. Butyrate enhances disease resistance of chickens by inducing antimicrobial host defense peptide gene expression. PLoS one. 2011;6: e27225.

56. Sunkara LT, Jiang W, Zhang G. Modulation of antimicrobial host defense peptide gene expression by free fatty acids. PLoS one. 2012;7:e49558.

57. Schauber J, Svanholm C, Termen S, Iffland K, Menzel T, Scheppach W, et al. Expression of the cathelicidin LL-37 is modulated by short chain fatty acids in colonocytes: relevance of signalling pathways. Gut. 2003;52:735-41

58. Ikezaki H, Furusyo N, Jacques PF, Shimizu M, Murata M, Schaefer EJ, et al. Higher dietary cholesterol and $\omega-3$ fatty acid intakes are associated with a lower success rate of Helicobacter pylori eradication therapy in Japan. Am J Clin Nutr. 2017;106:581-88.

59. Pretto JB, Cechinel V, Noldin VF, Sartori MRK, Isaias DEB, Bella CAZ. Antimicrobial activity of fractions and compounds from Calophyllum brasiliense (Clusiaceae/Guttiferae). Z Naturforsch C. 2004;59:657-62.

60. Nicolson K, Evans G, Otoole PW. Potentiation of methicillin activity against methicillin-resistant Staphylococcus aureus by diterpenes. FEMS Microbiol Lett. 1999;179:233-9.

61. Liu PT, Stenger S, Li H, Wenzel L, Tan BH, Krutzik SR, et al. Toll-like receptor triggering of a vitamin D-mediated human antimicrobial response. Science. 2006;311:1770-3.

62. D'Elia JA, Weinrauch LA.Calcium Ion Channels: Roles in Infection and Sepsis Mechanisms of Calcium Channel Blocker Benefits in Immunocompromised Patients at Risk for Infection. Int J Mol Sci. 2018;19:E2465

63. Jeng L, Yamshchikov AV, Judd SE, Blumberg HM, Martin GS, Ziegler TR, et al. Alterations in vitamin D status and anti-microbial peptide levels in patients in the intensive care unit with sepsis. J Transl Med. 2009;7:28.

64. Razzaque MS. The FGF23-Klotho axis: endocrine regulation of phosphate homeostasis. Nat Rev Endocrinol. 2009;5:611-9.

65. Kestenbaum B, Sampson JN, Rudser KD, Patterson DJ, Seliger SL, Young B, et al. Serum phosphate levels and mortality risk among people with chronic kidney disease. J Am Soc Nephrol. 2005;16:520-8.

66. Nykjaer A, Dragun D, Walther D, Vorum H, Jacobsen C, Herz J, et al. An endocytic pathway essential for renal uptake and activation of the steroid 25-(OH) vitamin D3. Cell. 1999;96:507-15.

67. Dial S, Nessim SJ, Kezouh A, Benisty J, Suissa S. Antihypertensive agents acting on the renin-angiotensin system and the risk of sepsis. $\mathrm{Br} \mathrm{J}$ Clin Pharmacol. 2014;78:1151-8.

68. Fliser D, Kollerits B, Neyer U, Ankerst DP, Lhotta K, Lingenhel A, et al. Fibroblast growth factor 23 (FGF23) predicts progression of chronic kidney disease: the Mild to Moderate Kidney Disease (MMKD) Study. J Am Soc Nephrol. 2007;18:2600-8.

69. Gudmundsson GH, Bergman P, Andersson J, Raqib R, Agerberth B. Battle and balance at mucosal surfaces-the story of Shigella and antimicrobial peptides. Biochem Biophys Res Commun. 2010;396:116-9.

70. Bowdish DM, Davidson DJ, Hancock RE. Immunomodulatory properties of defensins and cathelicidins. Curr Top Microbiol Immunol. 2006;306:27-66

71. Dubin PJ, Kolls JK. Th17 cytokines and mucosal immunity. Immunol Rev. 2008;226:160-71.

72. Milner JD, Brenchley JM, Laurence A, Freeman AF, Hill BJ, Elias $\mathrm{KM}$, et al. Impaired $\mathrm{T}(\mathrm{H}) 17$ cell differentiation in subjects with autosomal dominant hyper-IgE syndrome. Nature. 2008;452:773-6.

73. Ferwerda B, Ferwerda G, Plantinga TS, Willment JA, Spriel ABvan, Venselaar $\mathrm{H}$, et al. Human dectin-1 deficiency and mucocutaneous fungal infections. N Engl J Med. 2009;361:1760-7.

74. Glocker EO, Hennigs A, Nabavi M, Schaffer AA, Woellner C, Salzer $\mathrm{U}$, et al. A homozygous CARD9 mutation in a family with susceptibility to fungal infections. N Engl J Med. 2009;361:1727-35.

75. Stead WW, Senner JW, Reddick WT, Lofgren JP. Racial differences in susceptibility to infection by Mycobacterium tuberculosis. N Engl J Med. 1990;322:422-7.

76. Martineau AR, Nhamoyebonde S, Oni T, Rangaka MX, Marais S, Bangani $\mathrm{N}$, et al. Reciprocal seasonal variation in vitamin $\mathrm{D}$ status and tuberculosis notifications in Cape Town, South Africa. Proc Natl Acad Sci U S A. 2011:108:19013-7.

77. Nahid P, Horne DJ, Jarlsberg LG, Reiner AP, Osmond D, Hopewell $\mathrm{PC}$, et al. Racial differences in tuberculosis infection in United States communities: the coronary artery risk development in young adults study. Clin Infect Dis. 2011;53:291-4.

78. Talat N, Perry S, Parsonnet J, Dawood G, Hussain R. Vitamin d deficiency and tuberculosis progression. Emerg Infect Dis. 2010;16:853-5.

79. Nielsen NO, Skifte T, Andersson M, Wohlfahrt J , Soborg B, Koch A et al. Both high and low serum vitamin D concentrations are associated with tuberculosis: a case-control study in Greenland. Br J Nutr. 2010;104:1487-91.

80. Anand PK, Kaul D, Sharma M. Synergistic action of vitamin D and retinoic acid restricts invasion of macrophages by pathogenic mycobacteria. J Microbiol Immunol Infect. 2008;41:17-25.

81. Hmama Z, Sendide K, Talal A, Garcia R, Dobos K, Reiner NE. Quantitative analysis of phagolysosome fusion in intact cells: inhibition by mycobacterial lipoarabinomannan and rescue by an 1alpha,25dihydroxyvitamin D3-phosphoinositide 3-kinase pathway. J Cell Sci. 2004;117:2131-40.

82. Liu PT, Stenger S, Tang DH, Modlin RL. Cutting edge: vitamin Dmediated human antimicrobial activity against Mycobacterium tuberculosis is dependent on the induction of cathelicidin. J Immunol. 2007;179:2060-3.

83. Martineau AR, Wilkinson KA, Newton SM, Floto RA, Norman AW, Skolimowska K, et al. IFN-gamma- and TNF-independent vitamin D-inducible human suppression of mycobacteria: the role of cathelicidin LL-37. J Immunol. 2007:178:7190-8.

84. Sow FB, Alvarez GR, Gross RP, Satoskar AR, Schlesinger LS, Zwilling BS, et al. Role of STAT1, NF-kappaB, and C/EBPbeta in the macrophage transcriptional regulation of hepcidin by mycobacterial infection and IFN-gamma. J Leukoc Biol. 2009;86:1247-58.

85. Bacchetta J, Zaritsky JJ, Sea JL, Chun RF, Lisse TS, Zavala K, et al. Suppression of iron-regulatory hepcidin by vitamin D. J Am Soc Nephrol. 2014;25:564-72.

86. Xu H, Soruri A, Gieseler RK, Peters JH. 1,25-DihydroxyvitaminD3 exerts opposing effects to IL-4 on MHC class-II antigen expression, accessory activity, and phagocytosis of human monocytes. Scand J Immunol. 1993:38:535-40.

87. Berer A, Stockl J, Majdic O, Wagner T, Kollars M, Lechner K, et al. 1,25-Dihydroxyvitamin $\mathrm{D}(3)$ inhibits dendritic cell differentiation and maturation in vitro. Exp Hematol. 2000;28:575-83.

88. Griffin MD, Lutz WH, Phan VA, Bachman LA, McKean DJ, Kumar R. Potent inhibition of dendritic cell differentiation and maturation by vitamin D analogs. Biochem Biophys. Res Commun. 2000;270:701-8

89. Gauzzi MC, Purificato C, Donato K, Jin Y, Wang L, Daniel KC, et al. Suppressive effect of 1alpha,25-dihydroxyvitamin D3 on type I IFN-mediated monocyte differentiation into dendritic cells: impairment of functional activities and chemotaxis. J Immunol. 2005;174:270-6.

90. Pedersen AW, Holmstrom K, Jensen SS, Fuchs D, Rasmussen S Kvistborg $\mathrm{P}$, et al. Phenotypic and functional markers for 1alpha,25 dihydroxyvitamin $\mathrm{D}(3)$-modified regulatory dendritic cells. Clin Exp Immunol. 2009; $157: 48-59$

91. Brincourt J. [Liquefying effect on suppurations of an oral dose of calciferol]. Presse Med. 1969;77:467-70

92. Range N, Changalucha J, Krarup H, Magnussen P, Andersen AB, Friis $\mathrm{H}$. The effect of multi-vitamin/mineral supplementation on mortality during treatment of pulmonary tuberculosis: a randomized two-by-two factorial trial in Mwanza, Tanzania. Br J Nutr. 2006;95:762-70.

93. Nursyam EW, Amin Z, Rumende CM. The effect of vitamin D as supplementary treatment in patients with moderately advanced pulmonary tuberculous lesion. Acta Med Indones. 2006:38:3-5.

94. Martineau AR, Wilkinson RJ, Wilkinson KA, Newton SM, Kampmann B, Hall BM, et al. A single dose of vitamin D enhances immunity to mycobacteria. Am J Respir Crit Care Med. 2007;176:208-13.

95. Sudarsanam TD, John J, Kang G, Mahendri V, Gerrior J, Franciosa M, et al. Pilot randomized trial of nutritional supplementation in patients with tuberculosis and HIV-tuberculosis coinfection receiving directly observed short-course chemotherapy for tuberculosis. Trop Med Int Health. 2011;16:699-706.

96. Choi KY, Chow LNY, Mookherjee N. Cationic host defence peptides: multifaceted role in immune modulation and inflammation. J Innate Immun. 2012;4:361-70.

97. Silva ON, Fuente-Núñez Cde la, Haney EF, Fensterseifer IC, Ribeiro SM, Porto WF, et al. An anti-infective synthetic peptide with dual antimicrobial and immunomodulatory activities. Sci Rep. 2016;6:35465.

98. Mueller M, Lindner B, Dedrick R, Schromm AB, Seydel U. Endotoxin: physical requirements for cell activation. J Endotoxin Res. 2005;11:299-303.

99. Anunthawana T, Fuente-Núñez Cde la, Hancock RE, Klaynongsruang S. Cationic amphipathic peptides KT2 and RT2 are taken up into bacterial cells and kill planktonic and biofilm bacteria. Biochim Biophys Acta. 2015;1848:1352-8.

100. Haney EF, Mansour SC, Hilchie AL, de la Fuente-Núñez, Hancock RE. High throughput screening methods for assessing antibiofilm and immunomodulatory activities of synthetic peptides. Peptides. 2015;71:276-85.

101. Christophers E, Henseler T. Contrasting disease patterns in psoriasis and atopic dermatitis. Arch Dermatol Res. 1987;279:S48-51.

102. Ong PY, Ohtake T, Brandt C, Strickland I, Boguniewicz M, Ganz T, et al. Endogenous antimicrobial peptides and skin infections in atopic dermatitis. N Engl J Med. 2002;347:1151-60.

103. Yamasaki K, Schauber J, Coda A, Lin H, Dorschner RA, Schechter $\mathrm{NM}$, et al. Kallikrein-mediated proteolysis regulates the antimicrobial effects of cathelicidins in skin. FASEB J. 2006;20:2068-80.

104. Pütsep K, Carlsson G, Boman HG, Andersson M. Deficiency of antibacterial peptides in patients with morbus Kostmann: an observation study. Lancet. 2002;360:1144

105. Kostmann R. Infantile genetic agranulocytosis; agranulocytosis infantilis hereditaria. Acta Paediatr Suppl. 1956;45:1-78.

106. Frohm M, Agerberth B, Ahangari G, Stâhle-Bäckdahl M, Lidén S, Wigzell $\mathrm{H}$, et al. The expression of the gene coding for the antibacterial peptide LL-37 is induced in human keratinocytes during inflammatory disorders. J Biol Chem. 1997;272:15258-63.

107. Chronnell CM, Ghali LR, Ali RS, Quinn AG, Holland DB, Bull JJ, et al. Human beta defensin-1 and -2 expression in human pilosebaceous units: upregulation in acne vulgaris lesions. J Invest Dermatol. 2001;117:1120-5.

108. Oono T, Huh WK, Shirafuji Y, Akiyama H, Iwatsuki K. Localization of human beta-defensin-2 and human neutrophil peptides in superficial folliculitis. Br J Dermatol. 2003;148:188-91.

109. Kreuter A, Hyun J, Skrygan M, Sommer A, Bastian A, Altmeyer P, et al. Ultraviolet A1-induced downregulation of human beta-defensins and interleukin-6 and interleukin-8 correlates with clinical improvement in localized scleroderma. Br J Dermatol. 2006;155:600-7.

110. Escher N, Spies-Weisshart B, Kaatz M, Melle C, Bleul A, Driesch D, et al. Identification of HNP3 as a tumour marker in CD4 + and CD4- lymphocytes of patients with cutaneous T-cell lymphoma. Eur J Cancer. 2006;42:249-55.

111. Gambichler T, Skrygan M, Huyn J, Bechara FG, Sand M, Altmeyer P, et al. Pattern of mRNA expression of beta-defensins in basal cell carcinoma. BMC Cancer. 2006;6:163. 
112. Frasca L, Lande R. Role of defensins and cathelicidin LL37 in autoimmune and auto-inflammatory diseases. Curr Pharm Biotechnol. 2012;13:1882-97.

113. Kahlenberg JM, Kaplan MJ. Little peptide, big effects: the role of LL-37 in inflammation and autoimmune disease. J Immunol. 2013;191:4895901 .

114. Laube DM, Yim S, Ryan LK, Kisich KO, Diamond G. Antimicrobial peptides in the airway. Curr Top Microbiol Immunol. 2006;306:153-82.

115. Coffelt SB, Marini FC, Watson K, Zwezdaryk KJ, Dembinski JL, LaMarca HL, et al. The pro-inflammatory peptide LL-37 promotes ovarian tumor progression through recruitment of multipotent mesenchymal stromal cells. Proc Natl Acad Sci U S A. 2009;106:3806-11.

116. Jin G, Innocent E, Chow B, Bian J, Dayan J, McCormick T, et al. Differential modulation of human beta-defensin-3 expression in human oral epithelial cells by HPV oncoproteins E6 and E7: potential implication in oral cancer. Infect Agent Cancer. 2012;7:O11.

117. Kishi A, Takamori Y, Ogawa K, Takano S, Tomita S, Tanigawa M, et al. Differential expression of granulysin and perforin by NK cells in cancer patients and correlation of impaired granulysin expression with progression of cancer. Cancer Immunol Immunother. 2002;50:604-14.
118. Luo G, Zhou Y, Yi W, Yi H. Lactotransferrin expression is downregulated and affects the mitogen-activated protein kinase pathway in gastric cancer. Oncol Lett. 2015;9:2409-13.

119. Steinmann J, Halldórsson S, Agerberth B, Gudmundsson GH Phenylbutyrate induces antimicrobial peptide expression. Antimicrob Agents Chemother. 2009;53:5127-33.

120. Gombart AF, Borregaard N, Koeffler HP. Cathelicidin antimicrobial peptide (CAMP) gene is a direct target of the vitamin D receptor and is strongly up-regulated in myeloid cells by 1,25-dihydroxyvitamin D3. FASEB J. 2005;19:1067-77.

121. Mily A, Rekha RS, Kamal SMM, Arifuzzaman ASM, Rahim Z, Khan L, et al. Significant effects of oral Phenylbutyrate and vitamin D adjunctive therapy in pulmonary tuberculosis: a randomized controlled trial. PLoS One. 2015; 10:e0138340.

122. Fuente-Núñez Cde la, Silva ON, Lu TK, Franco OL. Antimicrobial peptides: Role in human disease and potential as immunotherapies. Pharmacol Ther. 2017;178:132-40.

123. Does AMvan der, Bergman P, Agerberth B, Lindbom L. Induction of the human cathelicidin LL-37 as a novel treatment against bacterial infections. J Leukoc Biol. 2012;92:735-42. 